\title{
Iconografia, imaginário e expansão marítima: elementos para a reflexão sobre o ensino de história
}

\author{
Thais Nivia de Lima e Fonseca
}

Doutora em História Social pela Universidade de São Paulo (USP). Pós-doutora pela Universidade de Lisboa, Portugal. Professora do Departamento de Educação e do Programa de Pós-graduação da Universidade Federal de Minas Gerais (UFMG). Autora de, entre outros livros, História \& Ensino. Belo Horizonte: Autêntica, 2003. thais@fae.ufmg.br

RESUMO

A proposta do texto é discutir a questão do imaginário dos descobrimentos presente em fontes iconográficas no ensino de história. Neste sentido, aborda viagens marítimas e as apropriações feitas pelo ensino de história mediadas pelos livros didáticos e outros mecanismos como o vídeo e a internet.

PALAVRAS-CHAVE: iconografia; imaginário; expansão marítima.

\section{ABSTRACT}

The proposal of the text is to discuss the imaginary of discoveries presented in iconographic documents used to teach history. This way, it focuses maritime journeys and the appropriations made by history teaching, mediated by didactic books and other mechanisms as video and internet.

KEY WORDS: iconography; imaginary; maritime expansion. 


\section{Iconografia, imaginário e expansão marítima: elementos para a reflexão sobre o ensino de história}

\begin{abstract}
A historiografia contemporânea tem valorizado substancialmente a iconografia, retirando-a do âmbito quase exclusivo da História da Arte, no qual ela ficou encerrada durante muito tempo, e a História Cultural tem sido o campo privilegiado, mas não único, para a sua farta utilização como fonte de pesquisa. Não necessariamente como efeito dessa situação, mas estimulado por ela, o ensino de História está cada vez mais familiarizado com o uso das imagens. $\mathrm{Na}$ verdade, há muito tempo, desde quando elas passaram a integrar o material predominante nas aulas de História por meio dos livros didáticos. Eles são, sem dúvida, o principal suporte de circulação de documentos iconográficos na escola, e isso desde o século XIX, quando já se registrava a preocupação com a utilidade das imagens para o ensino de História.
\end{abstract}

Atualmente, além dos efeitos de uma historiografia atenta aos novos objetos, às novas abordagens e à diversidade de fontes, a proliferação da comunicação visual em suas mais diversas modalidades impõe a reflexão sobre a produção, as apropriações e o significado das imagens nas sociedades humanas em várias épocas. Expressão e testemunho dos universos culturais nos quais estão inseridas, as imagens, analisadas histórica e culturalmente, são fundamentais para a compreensão dos modos de viver e dos sistemas de valores de indivíduos e de coletividades, de suas relações sociais e de poder. Não se pode esquecer, ainda, de seu poder de persuasão, de presentificação e de perpetuação de determinadas representações, "propriedades" muito acentuadas quando se trata da difusão de imagens pelo ensino.

Tratar da questão do imaginário dos descobrimentos presente em fontes iconográficas, no ensino de História, implica numa dupla abordagem: a do imaginário construído pelos europeus e presente no momento das viagens marítimas dos séculos XV e XVI e a do imaginário reapropriado e perpetuado, entre outros mecanismos, por este ensino, com a mediação dos livros didáticos e de outros mecanismos, como o vídeo e a internet. A desconstrução de toda essa arquitetura é uma operação possível na pesquisa sobre o ensino de História praticado e sobre a história deste mesmo ensino.

Assim, por meio desta temática, procurarei indicar algumas possibilidades investigativas e também didáticas, considerando o ensino de História no Brasil num período de intensificação da incorporação de imagens nos livros didáticos, como foi a década de 1990, momento também marcado pela busca do estreitamento entre a produção historiográfica mais recente e o ensino de História. Mas ouso também pequenas incursões a outros momentos do século XX. Como recurso analítico, procuro perceber a presença e funções da imagem neste ensino por meio da sua análise na perspectiva do imaginário. 
Os descobrimentos portugueses tiveram seu perfil cultural marcado por crenças e valores que pareciam pouco condizentes com o avanço técnico e científico tão propalado como condição primordial para a realização da empresa marítima. A historiografia tradicional, tanto em Portugal quanto no Brasil, sempre procurou enfatizar a face "moderna" do Portugal quatrocentista, em tudo pioneiro diante de seus vizinhos europeus, e afastado do feudalismo clássico, de natureza estagnadora. Um exame mais acurado, contudo, aponta para a presença marcante do imaginário de herança medieval nas viagens portuguesas do século $\mathrm{XV}$, a impor dificuldades que pouco tinham a ver com problemas técnicos. Estes nem sempre conseguiam superar as crenças, já muito conhecidas, sobre a natureza fantástica e perigosa do "mar oceano", habitado por seres fantásticos de toda espécie, movido por clima hostil, repleto de armadilhas que ameaçavam o retorno seguro dos viajantes. Considerandose que o imaginário é reconhecido socialmente e percebido subjetivamente, dotado de existência histórica efetiva, não se pode tratá-lo como irreal, fantasioso ou ilusório, sob pena de cometermos o mesmo deslize atribuído à historiografia tradicional, segura da idéia de progresso, de civilização e de verdade, rígida em sua visão do tempo linear, que não admite a coexistência de tempos e ritmos diferentes. Perceber o imaginário como uma vivência histórica concreta a fazer sentido para os homens do seu tempo é condição para que se possa compreender como era possível, para navegadores, governantes, cosmógrafos e cartógrafos, crer nas possibilidades científicas da realização de viagens marítimas de longa distância e ao mesmo tempo esperar encontrar monstros e seres fantásticos em suas jornadas. Como nos lembra Mary del
Priore, "para nossos antepassados os monstros não eram uma representação, e sim um fato" (DEL PRIORE, 2000, p.15). Isso torna ainda mais significativa a presença de tal discussão no ensino de História, uma vez que é um caminho para a reflexão acerca da cultura, do tempo, da alteridade e da relativização histórica.

A convivência das populações européias com esses elementos do fantástico e do maravilhoso não era, portanto, incomum. Se o medo do oceano e a construção de suas representações monstruosas esteve, a princípio, ligado às invasões, pelo mar, de povos não cristãos na Alta Idade Média, a retomada cristã dos territórios ocupados levou à "cristianização do mar" (KRUS, 1998, p. 99). Ao mesmo tempo em que crescia a devoção a santos navegadores, o mar passava a ser também rota para o Paraíso e os templos cristãos ostentavam pinturas e esculturas com temas marinhos, inclusive aqueles saídos do bestiário clássico, como sereias e tritões. Além disso, a propagação desse imaginário se fazia, também, pela difusão dos relatos e descrições de viagens, orais e escritos, reforçados estes últimos pelas imagens publicadas nos livros e bastante difundidas, como Les secrets de l'histoire naturelle, de Charles d'Angoulême (sec. XV); Livre des Merveilles, de Odoric de Pordenone (sec.XIV); La manière et les faitures des monstres (sec.XIV).

As referências imaginárias acompanhavam os navegadores, numa mobilidade tal que permitia o aparecimento do reino das amazonas na África e na América, deslocavam o Paraíso terrestre da Ásia também para a América, forçando adaptações à realidade que certamente colaboraram para dar maior longevidade às imagens há muito construídas sobre o maravilhoso. O reino do Preste João foi, como já acentuaram vários estudos, um 
dos elementos mais constantes desse imaginário quatrocentista. $\mathrm{Na}$ Crônica de $D$. João II, escrita entre 1530 e 1533 por Garcia de Resende, relatava-se, entre tantos atos do dito rei português, a ordem dada em 1486 para uma expedição terrestre com vistas ao encontro do reino do Preste João, a quem "levaram suas cartas [de D. João II], em que Ihe dava conta de tudo o que pela costa de Guiné tinha descoberto, para saber se algumas daquelas terras eram perto de seus Reinos, e senhorios, para por elas se poderem comunicar, e prestar, e fazer com que a fé de Jesus Cristo fosse exaltada, mandando-lhe notificar o grande desejo que tinha de se poderem conhecer, e terem verdadeira amizade" (RESENDE, 1991, p. 94)

Doze anos mais tarde, já no reinado de D. Manuel, o Venturoso, a procura pelo reino do Preste João não havia esmorecido e no roteiro da viagem de Vasco da Gama o autor relatava que estando a expedição em Moçambique, foram informados "que o Preste João estava dali perto, e que tinha muitas cidades ao longo do mar, e que os moradores deles eram grandes mercadores e tinham grandes naus; mas que o Preste João estava muito dentro pelo sertão, e que não podiam lá ir senão em camelos" (ROTEIRO, 1998, p.47).

A cartografia tem sido um campo privilegiado para a análise desses elementos do imaginário presentes nesses instrumentos destinados à navegação e à definição do espaço físico, e profundamente associados aos avanços científicos do alvorecer da época moderna. Como uma forma de expressar o conhecimento do mundo, a cartografia, sobretudo entre os séculos XV e XVII, traria em si uma compreensão ampla acerca desse conhecimento, incluindo não somente aquilo que, para nós, habitualmente caracterizaria um mapa - os acidentes geográficos, a topografia, a localização das cidades e dos caminhos, a vegetação - como também as representações do "mundo vivo" das áreas cartografadas, isto é, seus habitantes, sua fauna, sua flora, seus costumes. Os profusos elementos iconográficos presentes na cartografia européia neste período integravam, portanto, uma ampla leitura do mundo representado, incluindo os aspectos desconhecidos, referidos a antigas tradições culturais. Percebe-se o caráter híbrido dessa cartografia como um espaço fronteiriço e representativo dos encontros, cada vez mais intensos, entre culturas distintas e a necessidade imposta aos europeus de dar inteligibilidade aos mundos "descobertos", dotando os mapas de um "cenário" que permitisse a visibilidade daquilo que, de certa forma, ainda fazia parte do universo incógnito (BORGES, 2001).

É dessa forma que a cartografia irá expressando, iconograficamente, sua compreensão das novas terras e novas gentes. A princípio profundamente impregnada das referências mais remotas do imaginário, ela vai, progressivamente, acrescentando e eliminando elementos, à medida em que o conhecimento se aprofunda com o avanço da expansão. Ao lado dela, os livros, sobretudo aqueles de relatos de viagens, apareciam também ilustrados da mesma forma. $\mathrm{Na}$ análise dessa questão não se pode, portanto, restringir-se ao século $\mathrm{XV}$, $\mathrm{O}$ dos descobrimentos propriamente ditos. Ao longo dos séculos XVI e XVII as representações iconográficas e escritas relativas aos descobrimentos e seus desdobramentos foram profusas, realizadas tanto por portugueses quanto por outros europeus. Quando pensamos naquelas relativas ao Brasil, por exemplo, não há como deixar de mencionar também os holandeses e os franceses.

Se a carta de Pero Vaz de Caminha e os outros relatos conhecidos sobre a chegada 
dos portugueses à América são modestos em referências ao maravilhoso e ao fantástico, não deixam de indicar a presença de concepções trazidas por eles, como a idéia de um mundo cristão e civilizado, contrastado com a barbárie de povos que sequer podiam se comunicar como os europeus e que, segundo eles, não tinham crença ou fé. Para Paulo Roberto Pereira a carta de Caminha é um testemunho da "reformulação de valores no confronto com o outro", tendo colaborado para "o fim da literatura fantástica a respeito de povos e regiões desconhecidas" (PEREIRA, 1999, p. 64-65). Há certo exagero nesta afirmação, sobretudo se considerarmos documentos posteriores, tanto escritos quanto iconográficos. Se não há referências a monstros e seres fantásticos, Caminha não deixa de enfatizar a exuberância da natureza da terra e de seus habitantes, elementos fortemente enraizados no imaginário sobre o Paraíso terreal, na visão edênica que os europeus terão, a princípio, sobre a América. Além disso, a construção das representações do continente como terra de desordens e de barbárie deve muito ao imaginário ligado às concepções religiosas acerca do bem e do mal, do Paraíso e do Inferno, atribuindo ao Novo Mundo, sua natureza e seus habitantes toda sorte de associações com o diabólico.

As práticas da antropofagia foram, neste sentido, fortes consolidadoras desse imaginário e marcaram profundamente as experiências de muitos europeus, portugueses ou não, em seus contatos com a América. A obra de Hans Staden, editada pela primeira vez em 1557, talvez seja uma das mais emblemáticas neste sentido, constituindo-se em notável documento escrito e iconográfico sobre a questão. As referências a esse mundo diabólico, no qual homens devoram homens, estenderam-se pelos séculos XVI e XVII, quando esses mitos são recontextualizados $e$ superdimensionados no Brasil, a ponto de continuarem a acender a curiosidade e o medo dos europeus até o século XIX, como se pode constatar em relatos de viajantes como o francês Auguste de Saint-Hilaire, ansioso por seu encontro com os índios Botocudos em Minas Gerais, afamados por seu canibalismo.

A presença dessa temática no ensino de História tem sido marcada, principalmente, pelos livros didáticos, cada vez mais ilustrados. Embora as ilustrações já estivessem sendo usadas em livros didáticos brasileiros desde meados do século XIX, foi a partir das primeiras décadas do século $X X$ que elas se tornaram peças importantes no ensino de História do Brasil. Pouco a pouco, junto aos textos narrativos, foram sendo incluídas ilustrações, visando fazer com que os alunos aprendessem também "pelos olhos", como sugeria Jonathas Serrano no início do século $X X$, espelhando-se no francês Ernest Lavisse, que insistia na necessidade de fazer com que as crianças vissem cenas históricas, para compreender a história.

A preferência dos autores e dos editores recaiu sobre imagens que dessem um certo de grau de "veracidade" aos fatos narrados nos livros, que não só estivessem em sintonia com as principais obras da historiografia que Ihes serviam de referência, mas também se harmonizassem com o estilo narrativo e épico dos textos didáticos. As imagens deveriam, na verdade, atuar como "registros visuais" dos fatos narrados nos textos. Assim, sobressaíram como representações predominantes, num primeiro momento, os retratos dos chamados "grandes vultos" envolvidos na empreitada marítima, juntamente com imagens oriundas de dois grupos de fontes. No primeiro, europeus que estiveram no Brasil do século XVI ao século XIX, como Jean de Léry, Hans Staden, Jean Baptiste Debret, Johann Moritz 
Rugendas. Vistos como testemunhas oculares do passado do país, seus registros eram considerados verossímeis e fidedignos, em consonância com a concepção de história predominante, na qual os documentos encerrariam a verdade. No segundo grupo as obras de pintores brasileiros do século XIX e inicio do XX, como Pedro Américo, Victor Meirelles, Benedito Calixto, Antônio Parreiras e Oscar Pereira da Silva, autores da chamada escola acadêmica, por meio de obras que representam episódios consagrados pela historiografia oficial. As obras desses artistas continuam, na verdade, a integrar o elenco de imagens na produção dos livros didáticos de História.

Parte significativa dos livros didáticos produzidos na década de 1990 abordou o tema dos descobrimentos de forma etapista e, fundamentalmente, determinista e fatalista, apresentando a história portuguesa como um caminho necessariamente voltado para o destino da expansão marítima, pela tradicional reunião das "condições favoráveis" para a expansão, únicas em Portugal, o que daria ao país o papel pioneiro no processo. Conseqüentemente, a chegada dos portugueses ao Brasil foi vista como um efeito quase "natural". O enfoque épico acentua o seu caráter heróico, simplificando um processo complexo, que esteve longe da harmonia e do consenso. A ausência de conflitos é expressa pela afirmação predominante de uma perfeita conjugação de interesses entre os vários grupos sociais portugueses, empenhados num grande projeto nacional, tendo a aventura atlântica como eixo.

Percebe-se ainda a pouca atenção dada às questões culturais inerentes ao processo histórico, no tocante aos condicionantes presentes, não apenas no movimento da expansão marítima portuguesa, como também no processo de colonização. Entre algumas das representações mais recorrentes ligadas às viagens portuguesas, há as que se referem ao caráter épico das viagens atlânticas e ao tom enaltecedor dado ao processo protagonizado pelas nações ibéricas. Havia uma preocupação de reforçar a idéia do perigo que as viagens marítimas do século XV representavam para os europeus em geral e para os portugueses em particular. As palavras "perigo", "aventura", "aventureiros", "riscos", "preocupação", "morte", "mistério", "desconhecido", "desafios", “obstáculos", "façanha", “ousadia" eram recorrentes nesses textos e geralmente reforçadas por ilustrações que representavam embarcações enfrentando os perigos dos mares, perigos reais e naturais ou perigos imaginários, situações de tensão enfrentadas tanto em alto mar quanto em terra, nos contatos com povos desconhecidos dos europeus. O acento no caráter épico das navegações era ainda mais forte, através de um recurso cada vez mais comum nos livros didáticos, ou seja, a comparação entre as viagens atlânticas do século XV e as viagens espaciais do século XX.

Ao mesmo tempo que a superioridade técnica dos navegadores portugueses era enaltecida, dando-Ihes a primazia no processo de expansão, os autores desses livros ressaltavam a precariedade das embarcações, construindo um discurso contraditório. Assim, em alguns momentos indicavam a grande experiência em navegação e construção naval dos portugueses como sua vantagem em relação aos outros europeus e, em outros, a fim de acentuar o tom heróico e épico daquelas empreitadas, ressaltavam a fragilidade e a precariedade, tanto dos navios, quanto das condições de navegação, valorizando o corajoso enfrentamento dos mares protagonizado pelos portugueses no século $X V$. Superficiais, os textos não exploravam essa situação culturalmente rica, 
absolutizando as duas condições - a da superioridade naval e a do perigo das viagens -, perdendo a dimensão da complexidade e da pluralidade da história vivida.

Esta valorização da epopéia era ainda reforçada pela ênfase que recaía sobre as crenças comuns aos europeus no limiar do século $X V$, ligadas à existência de seres malignos habitantes dos mares, à geografia pouco segura do planeta, tudo aumentando as possibilidades do perigo e da morte iminentes. Muitas vezes, os textos didáticos dos anos 90, no entanto, ao invés de trabalharem essas questões como parte do universo cultural europeu do período, enfatizavam uma visão preconceituosa, tratando tais crenças apenas como fruto de superstição e de ignorância, olhando-as com as referências do senso comum do homem contemporâneo. Essa atitude acabava por contribuir para a consolidação de visões de mundo autocentradas, desprovidas de um sentido de alteridade, de compreensão do outro, levando seus leitores - em geral crianças e adolescentes - a tomarem seu próprio mundo como referência padrão para a compreensão dos demais, estabelecendo comparações que poderiam levar à formação de concepções conservadoras e preconceituosas. Além disso, deixavam entrever a idéia de que a modernidade, entendida como a expressão do mundo contemporâneo, curaria todas as superstições e ignorâncias, e que a ciência seria a redentora da mentalidade civilizada.

Como as imagens estariam balizando todas essas concepções, muito fortemente presentes no cotidiano do ensino de História, no momento em que se discutia a maior conexão entre a historiografia e o ensino, nos anos 90? Como discutir, ainda hoje, o imaginário como elemento conformador das representações que os homens fazem de si e do mundo? Como tornar essa discussão útil e necessária para a pesquisa sobre o ensino de História?

O uso da iconografia no ensino de História, como parte da produção de conhecimento, implica no seu tratamento na perspectiva do trabalho com as fontes de pesquisa do historiador. Como qualquer outro documento, a imagem é expressão e testemunho de um determinado universo cultural, de uma determinada conjuntura, situados no tempo. Da mesma forma que no trato de documentos escritos, o historiador, ao utilizar a imagem como fonte, não pode prescindir de uma análise que leve estas questões em consideração: a produção do documento, por quem, quando, com que objetivos, qual a sua estrutura, qual a origem e o destino do discurso, de que elementos se compõe. Trata-se, enfim, da prática da velha crítica documental, da qual todos ouvimos falar em nossos cursos de graduação, mas que pouco usamos na sala de aula do ensino básico. Além disso, deve-se estar atento à necessidade de confronto com outros documentos iconográficos e, se for o caso, com documentos de outra natureza, como os escritos e os da cultura material, por exemplo.

A iconografia existente sobre o imaginário dos descobrimentos é rica quantitativa e qualitativamente mas, curiosamente, o material mais utilizado nas salas de aula é pobre em imagens sobre o tema. Não obstante muitas edições recentes de livros didáticos tratem do imaginário medieval europeu a respeito de terras desconhecidas, são poucos os documentos iconográficos incorporados a esses textos. Quando aparecem, são algumas gravuras mostrando monstros atacando navios, seres fantásticos que habitariam as terras incógnitas, ou reproduções de mapas antigos, decorados com elementos desse imaginário. Vale 
lembrar, no entanto, que o ensino de História tem sido significativamente enriquecido com a publicação, desde o final dos anos 80 , de interessante material paradidático dedicado à temática das navegações e da expansão marítima européia da época moderna, incorporando a discussão sobre o imaginário, por meio da utilização de fontes escritas e iconográficas, em análises sustentadas pela História Cultural.

Assim como a maioria das imagens presentes nos livros - cujo sentido implícito é a confirmação da veracidade dos fatos narrados nos textos - a iconografia sobre o imaginário europeu da época dos descobrimentos é apresentada para confirmar que os europeus estavam errados a respeito daquilo que imaginavam ser 0 mundo da época, reforçando, portanto, uma idéia de falsidade, de ignorância e de superstição, isto é, tudo aquilo em que o espírito racional e moderno não deve acreditar. Seriam imagens canônicas, mas ao inverso de seu sentido original, isto é, estão incorporadas ao imaginário coletivo no sentido contrário. Está aqui um bom ponto de partida para a pesquisa sobre o tema, aplicada ao ensino de História usando-se as imagens: por que as crenças em monstros e maravilhas, em reinos fantásticos e riquezas sem conta não eram absurdas para os europeus naquela época? O que determina que o comportamento do homem contemporâneo deva ser diferente? Ele é absolutamente diferente? Quais as possibilidades da permanência de crenças semelhantes nos nossos dias?

O exame da cartografia dos séculos XIV, XV e XVI é um interessante ponto de partida para a reflexão sobre o imaginário dos descobrimentos no ensino de História. Ela expressa de maneira significativa o universo cultural europeu do final da Idade Média e do início dos tempos modernos, pois representa uma visão científica do mundo e está, ao mesmo tempo, impregnada de elementos de uma visão mítica: ao lado das definições geográficas, por exemplo, os mapas apresentavam indicações da existência de mundos míticos - como o reino do Preste João e a célebre ilha Brazil - até a localização exata do Paraíso, além da ocorrência de habitantes indesejáveis e perigosos espalhados pelo "mar tenebroso". A análise conjunta desses mapas com textos da época, alusivos a todos esses elementos, é um procedimento eficaz se se deseja desconstruir noções arraigadas acerca de barbárie e civilização, atraso e progresso, ciência e superstição. Este é um exercício de relativização e de reflexão sobre a historicidade dos universos culturais, sobre as situações de permanência e de mudanças, situando as condições de construção de sistemas de valores e de suas relações com as dinâmicas sociais em determinadas épocas. Vale também para a reflexão sobre a relação entre o passado e o presente e as diversas formas de apropriação de um pelo outro, com suas possibilidades de distanciamento e/ou aproximação.

Por fim, atendo-me brevemente às questões praticas do ensino de História, penso que o trabalho em sala de aula com o documento iconográfico, cotejado a outros, como por exemplo, para o tema em análise, os diários de viagem de navegadores dos séculos $\mathrm{XV}$ e $\mathrm{XVI}$, é um exercício de desconstrução e, ao mesmo tempo, construção de conhecimento que, embora já elaborado historiograficamente nos meios acadêmicos, pode ser reelaborado pelo estudante do ensino básico. Se o resultado "historiográfico" é mais ou menos previsível, o procedimento metodológico tem grande valor como forma de iniciação à atividade 
investigativa, ao final da qual resultarão conceitos fundamentais para a compreensão do processo histórico, sobretudo o entendimento da história como experiência vivida e como construção intelectual.

Falar nessas práticas implica, também, na sua realização junto aos estudantes de graduação, futuros professores. É necessário jamais perder de vista a íntima relação entre o ensino e a pesquisa, em suas mais diversas dimensões: a relação entre a produção acadêmica do conhecimento histórico e sua discussão e efetivação na graduação; a relação entre este conhecimento e o ensino básico; a relação entre o ensino de História na escola básica e a prática de procedimentos de pesquisa e de produção do conhecimento nesta escola. Se não há fórmulas para se "criar" um bom professor ou bom pesquisador, isolar as práticas do ensino e da pesquisa, desde os cursos de graduação, é comprometer a formação tanto de um quanto de outro. Mesmo aquele que optar por jamais entrar numa sala de aula de $5^{\mathrm{a}}$ série, se seguir a carreira acadêmica acabará diante da tarefa de formar aqueles que um dia o farão. Talvez devamos nos lembrar com mais frequência das motivações que nos levam a nos dedicarmos ao estudo da História, da satisfação que temos em "vivê-la", e de como seria lamentável negar tudo isso às crianças e aos jovens, apartando da formação acadêmica a preocupação com o ensino e deixando-o à mercê da mera transmissão de saberes. Lembremo-nos de Fernand Braudel, para quem "a viagem que é sua lição [de História] não deverá conduzir a terras mortas. É uma forma de incursão na vida passada em toda a sua ebulição. $\mathrm{O}$ adolescente que nos ouve tem a tendência de preferir o presente a este passado de idéias abstratas. Faça-os viver na realidade da história, entre as coisas concretas" (BRAUDEL, 2001, p. 123). Para isso, a imagem no ensino de História pode dar a vivacidade que queremos para ele, incentivando incrivelmente reflexão.

\section{Referências Bibliográficas:}

BACZKO, Bronislaw. Les imaginaires sociaux: mémoires et espoirs collectifs. Paris: Payot, 1984.

BARRETO, Luís Filipe \& GARCIA, José Manuel. Portugal na abertura do mundo. Lisboa: Comissão Nacional para as Comemorações dos Descobrimentos Portugueses, 1997.

BENNASSAR, Bartolomé. Dos mundos fechados à abertura do mundo. In: NOVAES, Adauto (org). A descoberta do homem e do mundo. São Paulo: Companhia das Letras, 1998.

BITTENCOURT, Circe (org). O saber histórico na sala de aula. São Paulo: Contexto, 1997.

BITTENCOURT, Circe Livro didático e conhecimento histórico: uma história do saber escolar. São Paulo: Universidade de São Paulo, 1993 (Tese de Doutorado)

BORGES, Maria Eliza Linhares. Cartografia, poder e imaginário: cartográfica portuguesa e terras de além-mar. In: SIMAN, Lana Mara de Castro \& FONSECA, Thais Nivia de Lima e. Inaugurando a História e construindo a nação: discursos e imagens no ensino de História. Belo Horizonte: Autêntica, 2001.

BRAUDEL, Fernand. La pédagogie de l'Histoire. In: L'Histoire au quotidien. Les écrits de Fernand Braudel. Paris: Éditions de Fallois, 2001.

CAPRETTINI, G.P. Imagem. In: Enciclopédia Einaudi. Volume 31: Signo. Lisboa: Imprensa Nacional-Casa da Moeda, 1994.

CAETANO, Joaquim Oliveira (coord). Gravura e conhecimento do mundo: o livro impresso ilustrado nas colecções da Biblioteca Nacional. Lisboa: Biblioteca Nacional, 1998.

COLI, Jorge. Primeira missa e invenção da descoberta. In: NOVAES, Adauto (org). A descoberta do homem e do mundo. São Paulo: Companhia das Letras, 1998. 
COLI, Jorge. A pintura e o olhar sobre si: Victor Meireles e a invenção de uma história visual no século XIX brasileiro. In: FREITAS, Marcos Cezar de (org). Historiografia brasileira em perspectiva. São Paulo: Contexto, 1998.

COLOMBO, Cristóvão. Diários da descoberta da América. 4 ed. Porto Alegre: L\&PM, 1987.

DEL PRIORE, Mary. A história cultural entre monstros e maravilhas. In: SWAIN, Tania Navarro (org). História no Plural. Brasília: Editora Universidade de Brasília, 1994.

DEL PRIORE, Mary. Esquecidos por Deus: monstros no mundo europeu e ibero-americano (séculos XVI-XVIII). São Paulo: Companhia das Letras, 2000.

FONSECA, Thais Nivia de Lima e. "Ver para compreender": arte, livro didático e a história da nação. In: SIMAN, Lana Mara de Castro \& FONSECA, Thais Nivia de Lima e. Inaugurando a História e construindo a nação: discursos e imagens no ensino de História. Belo Horizonte: Autêntica, 2001.

HOLANDA, Sérgio Buarque de. Visão do Paraíso: os motivos edênicos no descobrimento e colonização do Brasil. 4 ed. São Paulo: Nacional, 1985.

HOLLANDA, Guy de. Um quarto de século de programas e compêndios de História para o ensino secundário brasileiro (1931-1956). Rio de Janeiro: Instituto Nacional de Pesquisas Educacionais/Ministério da Educação e Cultura, 1957.

KRUS, Luis. O imaginário português e os medos do mar. In: NOVAES, Adauto (org). A descoberta do homem e do mundo. São Paulo: Companhia das Letras, 1998.
LAS CASAS, Frei Bartolomé. O paraíso destruído: brevíssima relação da destruição das Índias. 5 ed. Porto Alegre: L\&PM, 1991.

LAVISSE, Ernest. Histoire de France: cours élémentaire. Paris: Armand Colin, 1887.

MARIN, Louis. Des pouvoirs de l'image. Paris: Éditions du Seuil, 1993.

NORA, Pierre. Lavisse, instituteur national. In: Les lieux de mémoire. Paris: Quarto/Gallimard, 1997.

SALIBA, Elias Thomé. Experiências e representações sociais: reflexões sobre o uso e consumo de imagens. In: BITTENCOURT, Circe (org). O saber histórico na sala de aula. São Paulo: Contexto, 1997.

SALIBA, Elias Thomé. As imagens canônicas e o ensino de História. In: SCHMIDT, Maria Auxiliadora \& CAINELLI, Marlene Rosa (orgs). III Encontro Perspectivas do Ensino de História. Curitiba: Aos Quatro Ventos, 1999.

SANTOS, João Marinho dos. A expansão pela espada e pela cruz. In: NOVAES, Adauto (org). A descoberta do homem e do mundo. São Paulo: Companhia das Letras, 1998.

SERRANO, Jonathas. Epítome de História Universal. 24 ed. Rio de Janeiro: Livraria Francisco Alves, 1954. (Prefácio de 1918)

VAINFAS, Ronaldo. A problemática das utopias no contexto dos descobrimentos e da colonização da América. In: MONTEIRO, John Manuel \& BLAJ, llana (org). História \& Utopias. São Paulo: Associação Nacional de História, 1996.

VESPÚCIO, Américo. Novo Mundo: cartas de viagens e descobertas. Porto Alegre: L\&PM, 1984. 